\title{
Hubungan Personal Hygiene dan Sanitasi Lingkungan dengan Kejadian Penyakit Kecacingan
}

Nurfachanti Fattah', Arina F. Arifin², Santriani Hadi ${ }^{*}$, Fathul Rachmat S. Imam ${ }^{3}$

${ }^{1}$ Departemen Parasitologi, Fakultas Kedokteran, Universitas Muslim Indonesia, Makassar, Indonesia

${ }^{2}$ Departemen Histologi, Fakultas Kedokteran, Universitas Muslim Indonesia, Makassar, Indonesia

${ }^{3}$ Mahasiswa Fakultas Kedokteran, Universitas Muslim Indonesia, Makassar, Indonesia

*Corresponding Author. E-mail: nurfachanti.fattah@umi.ac.id, Mobile number: +62 852-4210-6290

\begin{abstract}
ABSTRAK
Latar belakang: Kecacingan merupakan masalah kesehatan yang tersebar luas didaerah tropis dan subtropis. Personal hygiene dan sanitasi lingkungan yang kurang baik pada anak-anak merupakan faktor yang mempermudah penularan kecacingan. Salah satu cara untuk memberantas kecacingan adalah dengan menghilangkan faktor-faktor yang memudahkan terjadinya penularan salah satunya adalah keadaan hygiene atau perilaku hidup dan sanitasi lingkungan.

Metode: Penelitian ini menggunakan desain analitik obsevasioanal, dengan pendekatan cross sectional. Sampel pada penelitian ini adalah total sampling dengan mengambil seluruh siswa-siswi di salah satu sekolah dasar, wilayah kerja puskesmas Tabaringan. Terdiri dari kelas 4 dengan jumlah siswa 25 orang; kelas 5 dengan jumlah siswa 20 dan kelas 6 dengan jumlah siswa 20 orang. Alat ukur yang digunakan adalah kuisioner, lembar observasi dan pemeriksaan laboratorium feses diperoleh dengan cara kunjungan ke sekolah dasar, tempat tinggal subyek, dan puskesmas Tabaringan.

Hasil: Adanya hubungan antara kebiasaan mencuci tangan $(\rho=0,048)$, kebersihan kuku $(\rho=0,014)$, kebiasaan jajanan $(\rho=0,035)$, kebiasaan BAB $(\rho=0,009)$, penggunaan air bersih $(\rho=0,002)$, pembuangan air limbah $(\rho=0,025)$, pembuangan kotoran $(\rho=0,048)$ dengan kejadian cacingan pada siswa.

Kesimpulan: Ada hubungan personal hygiene dan sanitasi lingkungan dengan kejadian cacingan pada siswa sekolah dasar di wilayah kerja Puskesmas Tabaringan Makassar.
\end{abstract}

Kata Kunci: Personal Hygiene; sanitasi lingkungan; kejadian penyakit kecacingan

Article history:

Received: 01 Mei 2020

Accepted: 23 Juni 2020

Published: 28 Desember2020

UMI MEDICAL JOURNAL

Published by :

Fakultas Kedokteran

Universitas Muslim Indonesia

Phone:

+6282293330002

\section{Address:}

Jl. Urip Sumoharjo Km. 5 (Kampus II UMI)

Makassar, Sulawesi Selatan.

Email:

medicaljournal@umi.ac.id 


\section{ABTRACT}

Background: Worming is a widespread health problem in tropical and subtropical regions. Personal hygiene and poor environmental sanitation in children are factors that facilitate transmission of helminthiasis. One way to eradicate helminthiasis is to eliminate factors that facilitate transmission, one of which is a state of hygiene or living behavior and environmental sanitation.

Method: This study used an observational analytic design, with a cross sectional approach. The sample in this study was total sampling by taking all students in one of the elementary schools, the working area of the Tabaringan Health Center. Consisting of grade 4 with 25 students; class 5 with 20 students and class 6 with 20 students. The measuring instruments used were questionnaires, observation sheets and fecal laboratory examinations obtained by visiting the elementary school, the subject's residence, and the Tabaringan health center.

Results: There was a relationship between hand washing habits $(\rho=0.048)$, nail hygiene $(\rho=0.014)$, snack habits $(\rho=0.035)$, bowel habits $(\rho=0.009)$, use of clean water $(\rho=0.002)$, waste water disposal $(\rho=0.025)$, waste disposal $(\rho=0.048)$ with the incidence of intestinal worms in students.

Conclusion: There is a relationship between personal hygiene and environmental sanitation with the incidence of intestinal worms in elementary school students in the work area of Tabaringan Makassar Health Center.

Keywords: Personal Hygiene; environment sanitation; intestinal worm infestation occurrence

\section{PENDAHULUAN}

Personal hygiene berasal dari bahasa Yunani, berasal dari kata 'personal' yang artinya perorangan dan 'hygiene' berarti sehat. Personal hygiene adalah suatu tindakan untuk memelihara kebersihan dan kesehatan seseorang untuk kesejahteraan baik fisik maupun psikisnya. Macam-macam hygiene perorangan yaitu kebersihan kulit, kaki, tangan, dan kuku, perawatan rambut, perawatan rongga mulut dan gigi, perawatan mata, telinga dan hidung. Tujuan dari perawatan hygiene perorangan adalah meningkatkan derajat kesehatan seseorang, memelihara kebersihan diri seseorang, memperbaiki hygiene perorangan yang kurang, pencegahan penyakit, meningkatkan percaya diri seseorang dan menciptakan keindahan.(1) Menurut WHO, sanitasi lingkungan (environmental sanitation) adalah upaya pengendalian semua faktor lingkungan fisik manusia yang mungkin menimbulkan atau dapat menimbulkan hal-hal yang merugikan bagi perkembangan fisik, kesehatan $d$ an daya tahan hidup manusia.(2)

Sanitasi lingkungan dapat pula diartikan sebagai kegiatan yang ditujukan untuk meningkatkan dan mempertahankan standar kondisi lingkungan yang mendasar yang mempengaruhi kesejahteraan manusia. Kondisi tersebut mencakup pasokan air yang bersih dan aman, pembuangan limbah dari manusia, hewan dan industri yang efisien, perlindungan makanan dari kontaminasi biologis dan kimia, udara yang bersih dan aman; rumah yang bersih dan aman. Dari defenisi tersebut, tampak bahwa sanitasi lingkungan ditujukan untuk memenuhi persyaratan lingkungan yang sehat dan nyaman.(3)

Infeksi kecacingan yang penularannya melalui tanah atau Soil Transmmited helminth penyebabnya adalah Ascaris lumbricoides, Ancylostoma duodenale, Necator americanus, Trichuris trichiura dan Strongyloides stercoralis. Selain itu, infeksi kecacingan dapat meningkatkan kerentanan terhadap penyakit 
penting lainnya seperti malaria, TBC, diare dan anemia. $(4,5,6,7)$

Sulawesi Selatan adalah salah satu provinsi di Indonesia yang cukup menjadi perhatian selain karena potensi yang dimiliki dalam bidang ekonomi, perdagangan dan pariwisata. Berdasarkan data dari Dinas Kesehatan Kabupaten/Kota bahwa kota Makassar menjadi kota tertinggi penderita kasus kecacingan. Jumlah penderita kecacingan di Kota Makassar berdasarkan laporan Dinas Kesehatan Kabupaten/Kota mengalami peningkatan dari tahun 2013 (3.226 kasus), 2014 (3.266 kasus), 2015 (3.270 kasus),(7) 2016 (1.928 kasus), kasus kecacingan di Sulawesi Selatan didominasi oleh kelompok umur 6-15 tahun dengan jumlah kasus sebesar 3.943 pada tahun 2016.(8)

Berdasarkan hasil penelitian Nurhaitil et al. (2013) mengenai prevalensi infeksi kecacingan pada anak sekolah dasar kelas IV,V dan VI di wilayah pesisir kota Makassar tahun 2013 sebanyak 57\%. Prevalensi jenis cacing yang menginfeksi anak sekolah dasar kelas IV,V dan VI di wilayah pesisir kota Makassar adalah pada infeksi tunggal yaitu cacing Ascaris lumbricoides sebanyak $34 \%$ dan pada infeksi ganda, jenis cacing sebanyak 14\% untuk cacing Ascaris lumbricoides dan Trichuris Trichuria.(9)(10)

Secara umum keadaan personal hygiene pada anak usia sekolah masih belum diperhatikan sehingga akan menimbulkan masalah kesehatan. Masalah kesehatan tersebut meliputi perilaku hidup sehat, gangguan infeksi, gangguan pertumbuhan, gangguan perkembangan, gangguan perilaku dan gangguan belajar. Permasalahan perilaku sehat pada anak usia sekolah biasanya berkaitan dengan kebersihan perorangan dan lingkungan seperti gosok gigi yang baik dan benar, kebiasaan cuci tangan pakai sabun, kebersihan diri.(3) Kondisi sanitasi lingkungan sangat erat hubungannya dengan infestasi cacing pada anak sekolah dasar. Hal ini dikarenakan sanitasi lingkungan yang tidak memadai dapat menjadi sumber penularan cacing pada tubuh manusia. (11)

Salah satu cara untuk memberantas kecacingan adalah dengan menghilangkan factor-faktor yang memudahkan terjadinya penularan salah satunya adalah keadaan higiene atau perilaku hidup dan sanitasi lingkungan. Personal hygiene dan sanitasi lingkungan yang kurang baik pada anak-anak merupakan faktor yang mempermudah penularan kecacingan. Hal ini menjadi penting untuk dilakukan suatu penelitian yang akan mengkaji hubungan personal hygiene dan sanitasi lingkungan dengan kejadian penyakit kecacingan pada murid sekolah dasar.

\section{METODE}

Jenis penelitian yang dilakukan adalah penelitian analitik observasional, dengan pendekatan cross sectional yakni suatu penelitian (survey) analitik dimana dilakukan identifikasi subjek (kasus) yang telah terkena penyakit (efek), kemudian ditelusuri secara retrospektif ada atau tidak adanya faktor resiko yang berperan. Sampel pada penelitian ini adalah total sampling dengan mengambil seluruh siswa. Terdiri dari 
kelas 4 dengan jumlah siswa 25 orang; kelas 5 dengan jumlah siswa 20 dan kelas 6 dengan jumlah siswa 20 orang. Kriteria inklusi adalah siswa sekolah dasar pada wilayah kerja Puskesmas Tabaringan, dan bersedia membawa sampel fesesnya untuk diperiksa serta mengisi kuesioner, sedangkan untuk kriteria ekslusi adalah siswa yang tidak tidak membawa sampel feses.

Personal hygiene yang dilihat pada sampel yaitu kebiasaan mencuci tangan, memakai alas kaki, kebersihan kuku, kebersihan jajanan, kebersihan buang air besar (BAB), air bersih, pembuangan air limbah, pembuangan kotoran, pembuangan sampah.Tujuan penelitian ini untuk mengetahui hubungan personal hygiene dan sanitasi lingkungan dengan kejadian penyakit kecacingan pada Murid sekolah dasar di wilayah kerja Puskesmas Tabaringan Kota Makassar.

\section{HASIL}

\section{Analisis Univariat}

Tabel 1. Distribusi Frekuensi Responden Berdasarkan Karakteristik.

\begin{tabular}{ccccc}
\hline \multirow{2}{*}{ Karakteristik } & \multicolumn{2}{c}{ Cacingan $($ case $)$} & \multicolumn{2}{c}{$\begin{array}{c}\text { Tidak Cacingan } \\
\text { (control) }\end{array}$} \\
\cline { 2 - 5 } & $\mathbf{N}$ & $\mathbf{\%}$ & $\mathbf{n}$ & $\mathbf{\%}$ \\
\hline Jenis kelamin & & & & \\
Laki-laki & 4 & 36,3 & 5 & 21,8 \\
Perempuan & 7 & 63,7 & 18 & 78,2 \\
\hline Jumlah & 11 & 100 & 23 & 100 \\
\hline Umur & & & & \\
8-10 tahun & 11 & 100 & 16 & 69,5 \\
11-13 tahun & 0 & 0 & 7 & 30,5 \\
\hline Jumlah & 11 & 100 & 23 & 100 \\
\hline Kelas & 10 & 91 & 13 & 56,6 \\
4 & 0 & 0 & 5 & 21,7 \\
5 & 1 & 9 & 5 & 21,7 \\
6 & 11 & 100 & 23 & 100 \\
\hline Jumlah & & & &
\end{tabular}

Berdasarkan umur responden terbesar terdapat pada kelompok kasus yaitu pada kelompok umur 8-10 tahun sebanyak 11 anak (100\%) dan jumlah kelas responden terbesar terdapat pada kelas 4 Sekolah Dasar yaitu 10 anak pada kelompok kasus dan 13 anak (56,6\%) pada kelompok kontrol. 
Tabel 2. Distribusi Frekuensi Responden terhadap Personal Hygiene

\begin{tabular}{|c|c|c|c|c|}
\hline \multirow{2}{*}{ Kebiasaan Mencuci Tangan } & \multicolumn{2}{|c|}{ Cacingan (Case) } & \multicolumn{2}{|c|}{ Tidak Cacingan (Control) } \\
\hline & $\mathbf{N}$ & $\%$ & $\mathbf{N}$ & $\%$ \\
\hline Baik & 7 & 63,6 & 21 & 91,3 \\
\hline Buruk & 4 & 36,4 & 2 & 8,7 \\
\hline Jumlah & 11 & 100 & 23 & 100 \\
\hline Memakai Alas Kaki & $\mathbf{N}$ & $\%$ & $\mathbf{N}$ & $\%$ \\
\hline Baik & 8 & 72,7 & 22 & 95,7 \\
\hline Buruk & 3 & 27,3 & 1 & 4,3 \\
\hline Jumlah & 11 & 100 & 23 & 100 \\
\hline Kebersihan Kuku & $\mathbf{N}$ & $\%$ & $\mathbf{N}$ & $\%$ \\
\hline Baik & 7 & 63,6 & 22 & 95,7 \\
\hline Buruk & 4 & 36,4 & 1 & 4,3 \\
\hline Jumlah & 11 & 100 & 23 & 100 \\
\hline Kebersihan Jajanan & $\mathbf{N}$ & $\%$ & $\mathbf{N}$ & $\%$ \\
\hline Baik & 9 & 81,8 & 23 & 100 \\
\hline Buruk & 2 & 18,2 & 0 & 0 \\
\hline Jumlah & 11 & 100 & 23 & 100 \\
\hline Kebersihan BAB & $\mathbf{N}$ & $\%$ & $\mathbf{N}$ & $\%$ \\
\hline Baik & 8 & 72,7 & 23 & 100 \\
\hline Buruk & 3 & 27,3 & 0 & 0 \\
\hline Jumlah & 11 & 100 & 23 & 100 \\
\hline Air Bersih & $\mathbf{N}$ & $\%$ & $\mathbf{N}$ & $\%$ \\
\hline Baik & 7 & 63,6 & 23 & 100 \\
\hline Buruk & 4 & 36,4 & 0 & 0 \\
\hline Jumlah & 11 & 100 & 23 & 100 \\
\hline Pembuangan Air Limbah & $\mathbf{N}$ & $\%$ & $\mathbf{N}$ & $\%$ \\
\hline Baik & 0 & 0 & 8 & 41 \\
\hline Buruk & 11 & 100 & 15 & 59 \\
\hline Jumlah & 11 & 100 & 23 & 100 \\
\hline Pembuangan Kotoran & $\mathbf{N}$ & $\%$ & $\mathbf{N}$ & $\%$ \\
\hline Baik & 7 & 63,6 & 21 & 91,3 \\
\hline Buruk & 4 & 36,4 & 2 & 8,7 \\
\hline Jumlah & 11 & 100 & 23 & 100 \\
\hline Pembuangan Sampah & $\mathbf{N}$ & $\%$ & $\mathbf{N}$ & $\%$ \\
\hline Baik & 6 & 54,5 & 15 & 65,2 \\
\hline Buruk & 5 & 45,5 & 8 & 34,8 \\
\hline Jumlah & 11 & 100 & 23 & 100 \\
\hline
\end{tabular}

(Sumber : Data Primer)

Berdasarkan tabel 2. distribusi frekuensi responden terhadap persol hygiene yang baik pada kelompok kasus paling banyak berdasarkan kebersihan jajanan yaitu 9 anak (81.8\%) dan memakai alas kaki 
yaitu 8 anak (72.7\%), sedangkan perseonal hygiene yang buruk paling banyak terhadap pembuangan air limbah yaitu 11 anak (100\%).

Berdasarkan tabel 2. distribusi frekuensi responden terhadap persol hygiene yang baik pada kelompok kontrol paling banyak berdasarkan kebersihan kaki, memakai alas kaki yaitu 23 anak (100\%) dan kebersihan jajanan, kebersihan BAB, air bersih yaitu 22 anak (95.7\%), sedangkan perseonal hygiene yang buruk paling banyak terhadap pembuangan air limbah yaitu 15 anak (59\%).

\section{Analisis Bivariat}

Tabel 3. menunjukkan bahwa terdapat hubungan antara air bersih $(\mathrm{p}=0.002)$, kebersihan $\mathrm{BAB}$ $(\mathrm{p}=0.009)$, kebersihab kuku $(\mathrm{p}=0.014)$, kebersihan jajanan $(\mathrm{p}=0.035)$, kebersihan mencuci tangan $(\mathrm{p}=0.048)$, dan pembuangan kotoran $(\mathrm{p}=0.048)$ dengan kejadain cacingan.

Tabel 3. Hasil Uji Chi-Square Hubungan personal hygiene dan sanitasi lingkungan dengan Kejadian Cacingan

\begin{tabular}{|c|c|c|c|c|c|}
\hline \multirow{2}{*}{ Kebiasaan Mencuci Tangan } & \multicolumn{2}{|c|}{ Cacingan (case) } & \multicolumn{2}{|c|}{ Tidak Cacingan (Control) } & \multirow{2}{*}{$\mathbf{P}$} \\
\hline & $\mathbf{N}$ & $\%$ & $\mathbf{N}$ & $\%$ & \\
\hline Baik & 7 & 63,6 & 21 & 91,3 & 0,048 \\
\hline Buruk & 4 & 36,4 & 2 & 8,7 & \\
\hline Jumlah & 11 & 100 & 23 & 100 & \\
\hline Memakai Alas Kaki & $\mathbf{N}$ & $\%$ & $\mathbf{N}$ & $\%$ & \\
\hline Baik & 8 & 72,7 & 22 & 95,7 & 0,052 \\
\hline Buruk & 3 & 27,3 & 1 & 4,3 & \\
\hline Jumlah & 11 & 100 & 23 & 100 & \\
\hline Kebersihan Kuku & $\mathbf{N}$ & $\%$ & $\mathbf{N}$ & $\%$ & \\
\hline Baik & 7 & 63,6 & 22 & 95,7 & 0,014 \\
\hline Buruk & 4 & 36,4 & 1 & 4,3 & \\
\hline Jumlah & 11 & 100 & 23 & 100 & \\
\hline Kebersihan Jajanan & $\mathbf{N}$ & $\%$ & $\mathbf{N}$ & $\%$ & \\
\hline Baik & 9 & 81,8 & 23 & 100 & 0,035 \\
\hline Buruk & 2 & 18,2 & 0 & 0 & \\
\hline Jumlah & 11 & 100 & 23 & 100 & \\
\hline Kebersihan BAB & $\mathbf{N}$ & $\%$ & $\mathbf{N}$ & $\%$ & \\
\hline Baik & 8 & 72,7 & 23 & 100 & 0,009 \\
\hline Buruk & 3 & 27,3 & 0 & 0 & \\
\hline Jumlah & 11 & 100 & 23 & 100 & \\
\hline Air Bersih & $\mathbf{N}$ & $\%$ & $\mathbf{N}$ & $\%$ & \\
\hline Baik & 7 & 63,6 & 23 & 100 & 0,002 \\
\hline Buruk & 4 & 36,4 & 0 & 0 & \\
\hline Jumlah & 11 & 100 & 23 & 100 & \\
\hline Pembuangan Air Limbah & $\mathbf{N}$ & $\%$ & $\mathbf{N}$ & $\%$ & \\
\hline Baik & 0 & 0 & 8 & 41 & 0,025 \\
\hline Buruk & 11 & 100 & 15 & 59 & \\
\hline
\end{tabular}




\begin{tabular}{cccccc}
\hline Jumlah & 11 & 100 & 23 & 100 & \\
\hline Pembuangan Kotoran & $\mathbf{N}$ & $\mathbf{\%}$ & $\mathbf{N}$ & $\mathbf{\%}$ & \\
\hline Baik & 7 & 63,6 & 21 & 91,3 & 0,048 \\
Buruk & 4 & 36,4 & 2 & 8,7 & \\
\hline Jumlah & 11 & 100 & 23 & 100 & \\
\hline Pembuangan Sampah & $\mathbf{N}$ & $\mathbf{\%}$ & $\mathbf{N}$ & $\mathbf{\%}$ & \\
\hline Baik & 6 & 54,5 & 15 & 65,2 & 0,549 \\
Buruk & 5 & 45,5 & 8 & 34,8 & \\
\hline Jumlah & 11 & 100 & 23 & 100 & \\
\hline
\end{tabular}

\section{PEMBAHASAN}

Hasil penelitian menunjukkan dari 11 responden pada kelompok kasus terdapat 4 anak (30\%) yang memiliki kebiasaan mencuci tangan yang buruk. Kebanyakan penyakit cacingan ditularkan melalui tangan yang kotor. Kebersihan tangan sangat penting karena tidak ada bagian tubuh lainnya yang paling sering kontak dengn mikroorganisme selain tangan.(12)

Hasil analisis hubungan antara kebersihan kuku dengan kejadian cacingan diperoleh sebanyak 4 anak $(36,4 \%)$ kelompok kasus yang mengalami cacingan memiliki kuku yang kotor,kuku tangan yang panjang dan kotor menyebabkan tertimbunnya kotoran dan kuman penyakit. Islam adalah perintis pertama yang berbicara tentang bakteri dan kotoran yang dimasukkan kategori dengan istilah khabats, atau khataya. Telur cacing yang berada di tanah dapat pindah ke sela-sela jemari tangan atau terselip pada kuku. Sehingga saat memakan makanan, telur cacing yang melekat dibawah kuku yang panjang dan kotor akan ikut tertelan bersama makanan yang dimakan.(13)

Hasil penelitian menunjukkan dari kelompok kasus terdapat 2 anak (18,2\%) yang memiliki jajanan yang tidak bersih, perilaku anak jajan di sembarang tempat yang kebersihannya tidak dapat dikontrol oleh orang tua, tidak terlindung dan dapat tercemar oleh debu dan kotoran yang mengandung telur cacing, juga dapat menjadi sumber penularan infeksi kecacingan pada anak. Selain melalui tangan, transmisi telur cacing juga dapat melalui makanan dan minuman, terutama makanan jajanan yang tidak dikemas dan tidak tertutup rapat. Telur cacing yang ada di tanah/debu akan sampai pada makanan tersebut jika diterbangkan oleh angin atau dapat juga melalui lalat yang sebelumnya hinggap di tanah/selokan, sehingga kaki-kakinya membawa telur cacing tersebut, terutama pada jajanan yang tidak tertutup.(10)

Hasil penelitian menunjukkan pada kelompok kasus terdapat 3 anak (27,3\%) yang memiliki kebiasaan $\mathrm{BAB}$ yang buruk, perilaku BAB yang kurang baik dan di sembarang tempat diduga menjadi faktor risiko dalam infeksi cacing. Secara teoritik, telur cacing memerlukan media tanah untuk perkembangannya. Adanya telur cacing pada tinja penderita yang melakukan aktifitas BAB di tanah terbuka semakin memperbesar peluang penularan larva cacing pada masyarakat di sekitarnya.Penyebaran penyakit 
cacingan dapat melalui terkontaminasinya tanah dengan tinja yang mengandung telur Trichuris trichiura, telur tumbuh dalam tanah liat yang lembab dan tanah dengan suhu optimal $\pm 30^{\circ} \mathrm{C}$.(10)

Hasil penelitian menunjukkan pada kelompok kasus terdapat 11 rumah anak (100\%) yang memiliki pembuangan air limbah yang buruk, salah satu penyebab terjadinya pencemaran air adalah air limbah yang dibuang tanpa pengolahan terlebih dahulu ke dalam suatu badan air. Menurut Peraturan Pemerintah Republik Indonesia Nomor 82 Tahun 2001, air limbah adalah sisa dari suatu usaha dan/atau kegiatan yang berwujud cair. Air limbah dapat berasal dari rumah tangga (domestic) maupun industri (industry).(13)

Hasil penelitian menunjukkan pada kelompok kasus terdapat 4 rumah anak $(36,4 \%)$ yang memiliki pembuangan kotoran yang buruk. Dikutip dari pendapat Ditjen P2PL, jamban adalah suatu bangunan yang digunakan untuk membuang dan mengumpulkan kotoran manusia dalam suatu tempat tertentu dan tidak menjadi penyebab atau penyebar penyakit serta mengotori lingkungan pemukiman. Pembuangan tinja yang tidak saniter akan menyebabkan terjadinya berbagai penyakit seperti diare, kolera, disentri, kecacingan, dan sebagainya.(13)

\section{KESIMPULAN}

Hasil penelitian menunjukkan Adanya hubungan antara kebiasaan mencuci tangan, kebersihan kuku, kebiasaan jajanan, kebiasaan BAB, penggunaan air bersih, pembuangan air limbah, pembuangan kotoran dengan kejadian cacingan pada siswa.

\section{DAFTAR PUSTAKA}

1. Isro'in L. Personal Hygiene. 1st ed. Yogyakarta: Graha Ilmu; 2012.

2. Umar. Dasar-Dasar Kesehatan Lingkungan. Makassar: FKM UNHAS; 2003. 58 p.

3. Mahmudah U. Hubungan Sanitasi Lingkungan Rumah terhadap Kejadian Infeksi Kecacingan pada Anak Sekolah Dasar. J Kesehat. 2017.

4. Budiasri R, Hadju V, Sirajuddin S. Infeksi Kecacingan Dan Status Gizi pada Anak Sekolah Dasar di Wilayah Pesisir Kota Makassar. Progr Studi Ilmu Gizi Fak Kesehat Masy Univ Hasanuddin. 2013.

5. World Health Organisation (WHO). Eliminating soil-transmitted helminthiasis as a health problem in children: Progress report 2001-2010 and strategic plan 2011-2020. Geneva World Heal Organ. 2012 .

6. Tanjung TP. Gambaran Kebersihan Lingkungan Dan Kebersihan Pribadi pada Anak Usia Sekolah 
Dasar Yang Menderita Infeksi Kecacingan di Desa Kubu Colia Kecamatan Dolat Rayat Kabupaten Karo. Snr Kesmas Unefa. 2013;

7. Risma. Hubungan Status Sosial Ekonomi dengan Kejadian Kecacingan pada Siswa SD di Makassar Sulawesi Selatan. Skripsi Univ Hasanudin Makassar. 2017;

8. Maliya A, Susilaningsih EZ. Distribusi spasial kasus kecacingan (Ascaris lumbricoides) terhadap personal higiene anak balita di Pulau Kodingareng Kecamatan Ujung Tanah Kota Makassar Tahun 2016. J Epidemiol UIN Alauddin. 2016;2(2):74-80.

9. Samudar N, Hadju V, Jafar N. Hubungan Infeksi Kecacingan dengan Status Hemoglobin Pada Anak Sekolah Dasar Di Wilayah Pesisir Kota Makassar Propinsi Sulawesi Selatan Tahun 2013. J Univ Hasanuddin. 2013;

10. Dewi N LD. Hubungan perilaku higienitas diri dan sanitasi sekolah dengan infeksi Soil-transmitted helminths pada siswa kelas III-VI Sekolah Dasar Negeri No. 5 Delod Peken Tabanan Tahun 2014. E-Jurnal Med. 2017;

11. Kundaian F, Umboh JM., Kepel BJ. Hubungan Antara Sanitasi Lingkungan dengan Infestasi Cacing pada Murid Sekolah Dasar di Desa Teling Kecamatan Tombariri Kabupaten Minahasa. J KESMAS. 2012;

12. Umar Z. Perilaku Cuci Tangan Sebelum Makan dan Kecacingan pada Murid SD di Kabupaten Pesisir Selatan Sumatera Barat. Kesmas Natl Public Heal J. 2008;

13. Setyowatiningsih L, Surati S. Hubungan Higiene Sanitasi Dengan Kejadian Infeksi Soil Transmitted Helminths Pada Pemulung di Tps Jatibarang. J Ris Kesehat. 2017. 